\title{
Socratic Problem-Solving In The Business World
}

Evan Peterson, University Of Detroit Mercy, USA

\begin{abstract}
Accurate and effective decision-making is one of the most essential skills necessary for organizational success. The problem-solving process provides a systematic means of effectively recognizing, analyzing, and solving a dilemma. The key element in this process is critical analysis of the situation, which can be executed by a taking a Socratic approach to the situation. Applying the Socratic Method to the problem-solving model ensures a well-rounded and versatile analysis.
\end{abstract}

Keywords: Problem-solving process, decision- making, critical analysis, Socratic Method

\section{INTRODUCTION}

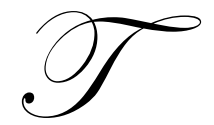

he sheer complexity of today's business organization is rivaled only by the complexity of the business environment in which it operates. The permutation of complexity and exacting time constraints companies and individuals face in making vital decisions involving thousands of people and millions of dollars can seem more daunting than storming the beaches of Normandy. However, all hope is not lost. The anxiety, along with the blood, sweat, and tears that come along with difficult decision-making can be reduced by having a clear, time-tested plan of attack that can be applied to the problem situation.

The problem-solving model is one such plan of attack, for it provides a framework that an individual decision-maker or group of decision-makers can follow to reach a feasible solution to the problem. Situational analysis is the bread and butter of the problem-solving model, for it goes hand-in-hand with each step of the model. Accordingly, is it vital that a proper, unbiased analysis of the situation be undertaken to ensure the ultimate solution is reliable.

\section{LITERATURE}

There are numerous versions and adaptations of the problem-solving model. For instance, the problemsolving process as described by Bergan (1977) contains four steps: problem identification, problem analysis, plan implementation, and problem evaluation. The formulation promulgated by Blai (1986) contains eight steps: analyze the problem situation, determine the problem, break problem down into component elements, develop alternative courses of action, determine outcome probability for each course, choose the best course, and decide on a plan/schedule for implementation. Other models include work by Conrath, 1985; Wasik \& Fishbein, 1982; Kratochwill \& Bergan, 1990; and Margolis \& Brannigan, 1987. While several of these models have unique aspects, they for the most part consist of several universal steps. ${ }^{1}$

Utilizing these models as a foundation, there are five different stages common to the bulk of the models: 1 . classification of the problem 2. generation of alternate solutions 3. decision-making 4. solution implementation, and 5. outcome evaluation. As suggested by VanGundy (1988), in order for problem-solving to be successful, the steps in the problem-solving process must be undertaken in a logical and systematic manner. ${ }^{2}$

\footnotetext{
${ }^{1}$ Jayanthi, M. and Friend, M. "Interpersonal Problem-solving: A Selective Literature Review to Guide Practice." Journal of Educational and Psychological Consultation, vol. 3, 39-51 (1992).

2 "Interpersonal Problem-solving: A Selective Literature Review to Guide Practice" at 42.
} 
What follows is a brief recap of the problem-solving process. It is not intended to be a complete description of the five common stages of the problem-solving process. Instead, it is intended to demonstrate that when proceeding through the five stages, there are countless situations where groups have the potential to disagree and certain facts can be open to interpretation.

The first step in the problem-solving process is to identify the problem at hand. As noted by Bergan \& Tombari (1975), accurately identifying the problem is a vital element in the problem-solving process. Part of this step is clarification or explanation of the problem. A variety of activities have been suggested as a means of clarifying the problem. For instance, the problem can be analyzed in terms of its frequency, duration, latency or intensity (Kratochwill \& Bergan, 1990; Witt \& Elliot, 1983). The problem can also be analyzed in terms of the characteristics of both the client and the consultee, their interactions with one another, and various environmental variables (Osterweil, 1987). A third possibility is obtaining information on the expected future performance levels (Bergan, 1977) or on a client's strengths/weaknesses (Bergan, 1977; Witt \& Elliot, 1983). ${ }^{3}$

The second step in the problem-solving process is generation of as many solutions as possible for the defined problem. A variety of practices are available to help generate constructive ideas. One approach is to encourage as many ideas as possible because idea quantity engenders idea quality (Basadur, Graen, \& Green, 1982; Bayless, 1967). That being said, generation of outrageous and wild ideas is encouraged (Glassman, 1989b; Grossman, 1984a). Another strategy is to use mental imagery, as discussed by Sarnoff \& Remer (1982) and Schwab \& D'Zamko (1988) to promote creative and innovative thinking. When group problem-solving is involved, a common theme of the images is derived and the problem's solution is developed based on that common theme. ${ }^{4}$

The third step in the problem-solving process is evaluating and selecting one solution from the list of possible solutions previously generated. This phase can entail a detailed explanation of certain charges required by each alternative (Kratochwill \& Bergan, 1990). It could also involve specifying information on feedback, expenses, time constraints, and interpersonal effects on the organization for each alternative (R. A. Kaufman, 1971; Wasik \& Fishbein, 1982). ${ }^{5}$

The fourth step entails actual implementation of the solution generated by the previous steps. It consists of two phases: pre-implementation and implementation. In the pre-implementation phase, activities can include assembling essential materials in order to carry out the plan (Kratochwill \& Bergan, 1990) and stimulating implementation to determine vulnerable elements and anticipate possible difficulties that will be encountered (Berry, 1983; Brightman \& Verhoeven, 1986). The implementation phase can involve monitoring solution implementation (Bergan, 1977), tracking actual versus expected progress (Brightman \& Verhoeven, 1986), and gathering data related to solution implementation (Peterson, Homer, \& Wonderlich, 1982). ${ }^{6}$

The fifth and final step examines outcome evaluation and focuses on several different issues. For instance, goal attainment is examined, with decisions being made based on judgments regarding similarity between established objectives and results data collected during implementation (Kratochwill \& Bergan, 1990). Also, metaevaluation occurs, whereby certain questions are asked, such as "Was the implemented solution effective relative to the desired benefits?" (Maher, 1981).

While the steps of the problem-solving model are important because they provide a framework to follow, it is important not to overlook the analysis contained within each of those steps. It is important in conducting the analysis associated with the above steps to ensure that assumptions and biases of the decision-makers are recognized, facts are not given over-inflated or under-inflated importance, information used as a basis for a decision is reliable and properly evaluated, etc. All of these issues are extremely important and could potentially have a drastic effect on the viability of the ultimate solution if overlooked. Therefore, in addition to having the systematic methodology

\footnotetext{
3 “Interpersonal Problem-solving: A Selective Literature Review to Guide Practice" at 42-43.

4 "Interpersonal Problem-solving: A Selective Literature Review to Guide Practice" at 45.

5 "Interpersonal Problem-solving: A Selective Literature Review to Guide Practice" at 47.

6 "Interpersonal Problem-solving: A Selective Literature Review to Guide Practice" 47-48.

7 "Interpersonal Problem-solving: A Selective Literature Review to Guide Practice" 49-50.
} 
provided by the problem-solving model, a decision-maker also needs to be able to critically evaluate facts, ideas, and scenarios associated with those steps. A Socratic approach, more formerly known as the Socratic Method, is an excellent means of promoting and developing this form of critical analysis.

\section{DISCUSSION}

The Socratic Method is a disciplined form of questioning that can be used to encourage abstract thought for a variety of purposes, including investigation of intricate and multifaceted issues, critical analysis, recognition of biases and assumptions, and consideration of the consequences of certain actions. ${ }^{8}$ The Socratic Method is the predominant teaching process employed by American law schools. However, because its purpose is to encourage analysis and critical thinking, it has the potential for numerous applications outside the law school setting. The Socratic Method is a means of actively engaging an individual in the critical thinking process. ${ }^{9}$

The Socratic Method begins with an individual posing an initial question, followed then by further questions in response to the answers received to the initial question. The process consists of a back and forth movement between proposals and counter proposals, in an effort to elicit more focused ideas centering on a general concept. ${ }^{10}$ The purpose is to assist the individual in reasoning his or her way to the solution to a problem scenario. The questioner encourages all forms of comments, identifies the need for modification, and asks further questions aimed at achieving that revision. The idea behind the concept is to prevent passive acceptance of an idea or fact and to challenge the individual to think independently (Rocklin 1987). ${ }^{11}$ The Socratic method takes analysis to the next level, probes deeper, not only looking at every presented fact and asking who, what, when, where, why, and how, but also trying to examine situations and facts not presented by the situation. It goes further by recognizing that there is always something that the decision-maker has not considered in conducting his or her analysis.

The Socratic Method, although not itself a problem-solving model, can be applied to the five steps of the decision-making process articulated above, which could ultimately result in better overall decision-making. Socratic questioning is like an art form; it may take time and practice for an individual to truly hone and develop flourishing skills. Nevertheless, some of the foundational techniques of the method, listed below, are relatively straightforward and can be immediately applied to each step of the decision-making process: ${ }^{12}$

- $\quad$ Ask an individual to provide instances or justifications for the position advocated

- Interject a counter-example in response to an individual's position or point

- $\quad$ Ask whether anyone in the group agrees with the position advocated

- $\quad$ Suggest a parallel example

- $\quad$ Illuminate a specific concept or position using an analogy

- $\quad$ Play the role of devil's advocate to an articulated position

The form of the Socratic questioning may take on a revised configuration depending on the circumstances. As noted above, the normal pattern of the Socratic Method is to have one individual ask a series of guided questions of other individuals, but, in fact, there are three possible ways the questioning process may unfold: 1. questions are posed by a superior to subordinates 2 . questions are posed by one peer to another and vice versa 3 . questions are posed and answered by the same individual. The first scenario will likely arise when a superior assigns a task to a

\footnotetext{
${ }^{8}$ Paul R. and Elder L. "Critical Thinking: The Art of Socratic Questioning.” Journal of Developmental Education. 31, 1, 36-37 (2007).

${ }^{9}$ Smith, H.W. "Comparative Evaluation of Three Teaching Methods of Quantitative Techniques: Traditional Lecture, Socratic Dialogue, and Psi Format." Journal of Experimental Education. 55, 3. 149-155 (1987).

${ }^{10}$ Howard, G. "Socrates and Technology a New Millennium Conversation." International Journal of Instructional Media, vol. 33 (2006).

${ }^{11}$ Overholser, J. "Socrates in the Classroom." College Teaching. 40, 1, 14-18 (1992).

${ }^{12}$ Paul, R. and Elder, L. "Critical Thinking: The Art of Socratic Questioning, Part III." Journal of Developmental Education. 31 , 3, 34-35 (2008).
} 
group of subordinates, but instead of leaving the subordinates to fend for themselves, the superior is continually present in a coaching type capacity. In such a situation, the normal outline of the Socratic model is maintained because the superior is able to guide the subordinates in the completion of their task by asking Socratic questions. The individual asking the questions in this scenario need not be an actual superior, but merely an individual who has a specialized knowledge of the subject matter above and beyond that possessed by the other members of the group.

Conversely, individuals can also find themselves in a situation where they are given a difficult task to complete by a superior and then left to complete it on their own. Here the ordinary formulation of the Socratic questioning is amended to fit the needs of the situation. Unlike the traditional application, the revised approach in this situation has the effect of giving each individual a dual role of both asking the guided Socratic questions and providing the answer to such questions. Thus, each individual also needs to develop the skills of proper Socratic questioning.

Questioning conducted in the peer-to-peer manner may even have benefits in addition to those provided by the superior-to-subordinate manner. Not only are individuals steered in their thinking by the guiding questions of their peers, but they will be that much stronger in responding to the questions because they will understand the method behind the questioning, and may therefore be able to reach a more feasible conclusion more quickly. There is a further advantage in that if the situation arises where the individual posing the questions becomes unsure of how to proceed, another individual may take the lead and ask the right question, allowing the group to move forward in its thought process.

Although it may seem like a bit of a contradiction, the Socratic questioning process can also be effective when conducted by a solitary individual. While the true strength of the process lies in the back-and-forth questioning between numerous individuals, a solitary individual can also benefit from the methodology by acting as his or her own devils advocate, asking the same critical questions that would be asked by other members of the discussion.

\section{CONCLUSION}

Effective decision-making is one of the most important issues affecting today's global organizations. Individuals are faced with making complicated decisions involving complex commercial or financial transactions, corporate restructuring, and corporate strategy. In order to ease the burden associated with this difficult process, the problem-solving model is a tool that can be used to guide a decision-maker's thinking through every step of the decision-making process.

Many different problem-solving models have been developed over the years, each possessing unique features. A common theme that re-occurs throughout each model is the concept of critical analysis. Each model, in one form or another, requires the decision-maker to perform an analysis of various factors, whether internal or external to the individual's organization. Critical thinking and such situational analyses go hand-in-hand. Critical examination of the issues associated with the problem is vitally important because it will help to ensure that biases and assumptions are put in check so that they do not affect the viability of the ultimate solution.

The Socratic Method provides a means of asking guided questions to allow decision-makers to critically analyze the facts associated with any given situation. By combining the systematic process developed by the problem-solving models with the practice of guided questions associated with the Socratic Method, the necessary level of critical analysis is conducted.

\section{AUTHOR INFORMATION}

Evan Peterson, JD, MBA teaches as an adjunct professor in the College of Business Administration at the University of Detroit Mercy. His areas of publication include scholarly articles on supply chain management, technology, decision making, innovative teaching methods, and the effects of legal the legal system on global business. He has been published in the Journal of Business \& Economics Research, American Journal of Business 
Education, and the College Teaching and Learning Journal. His current research interests focus on the effects of securities law on transnational transactions

\section{REFERENCES}

1. Jayanthi, M. and Friend, M. "Interpersonal Problem-solving: A Selective Literature Review to Guide Practice." Journal of Educational and Psychological Consultation, vol. 3, 39-51 (1992).

2. Howard, G. "Socrates and Technology a New Millennium Conversation." International Journal of Instructional Media, vol. 33 (2006).

3. Overholser, J. "Socrates in the Classroom." College Teaching. 40, 1, 14-18 (1992).

4. Paul R. and Elder L. "Critical Thinking: The Art of Socratic Questioning." Journal of Developmental Education. 31, 1, 36-37 (2007).

5. $\quad$ Paul, R. and Elder, L. "Critical Thinking: The Art of Socratic Questioning, Part III." Journal of Developmental Education. 31, 3, 34-35 (2008).

6. Smith, H.W. "Comparative Evaluation of Three Teaching Methods of Quantitative Techniques: Traditional Lecture, Socratic Dialogue, and Psi Format.” Journal of Experimental Education. 55, 3. 149155 (1987). 
NOTES 